\section{FRI0319 PREDICTORS OF COMPLETE REMISSION IN POLYMYALGIA RHEUMATICA}

D. Birra, A. Zoli, G. Peluso, S.L. Bosello, E. Gremese, G. Ferraccioli.

Dipartimento di Reumatologia e Scienze Affini, Università Cattolica del Sacro Cuore - Fondazione Policlinico Universitario Agostino Gemelli, Rome, Italy

Background: Polymyalgia rheumatica (PMR) is an inflammatory rheumatic condition characterized by aching and morning stiffness in the shoulders, hip girdle, and neck that typically occurs in adults over the age of 50 . A rapid resolution of symptoms with low-dose glucocorticoids is a feature of PMR although some patients may experience a disease flare-up during steroid tapering.

Objectives: The aim of the study was to investigate possible clinical or laboratory prognostic factors of remission during a 12 month follow up in PMR patients treated with a starting low prednisone dose following the 2015 ACR-EULAR guidelines ${ }^{(1)}$.

Methods: From 86 consecutive outpatients, diagnosed with PMR following ACR/EULAR 2012 provisional clinical criteria for PMR ${ }^{(2)}, 79$ patients (56 women and 23 men), that achieved a complete follow up of at least 12 months, were selected. Clinical evaluation and laboratory tests were performed every 3 months Clinical remission was defined as lack of shoulder and hip girdle pain and as levels of $E S R<40 \mathrm{~mm} / \mathrm{h}$ and $\mathrm{CRP} \leq 0.5 \mathrm{mg} / \mathrm{dl}$.

Results: 37 PMR patients reached a complete remission after twelve months follow-up. We didn't find any significant difference in the mean age and in ESR and CRP values at the beginning of the disease in patients in remission after 12 month of follow up when compared with patients not in remission. Presence of obesity, dyslipidemia, hypertension, diabetes and smoking habits were not significantly different in the two groups of patients. No significant difference in steroid therapy at the beginning and after 6 month of follow up was noted between the two groups of patients. A statistically significant female low clinical remission was seen at the end of 12 month follow up when compared with male complete clinical remission $(33.9 \%$ versus $78.2 \%, p=.000)$ Moreover it was shown that the patients achieving clinical and laboratory remission after six months of therapy were also those who maintained remission at the 12 month. CRP values, instead of ESR ones, were more predictive of remission after one year of therapy. Therefore patients with clinical remission in the absence of normalization of CRP value had greater risk of exacerbation.

Table 1. Demographic and laboratory characteristic of patients

\begin{tabular}{|c|c|c|c|}
\hline & Remis sion T12 & Non responders T12 & p. \\
\hline Age & $75.1 \pm 6.7$ & $69.7 \pm 5.7$ & ns \\
\hline $\mathrm{N}^{\circ}$ & 37 & 42 & \\
\hline Female & 19 & 37 & .000 \\
\hline ESR TO $(\mathrm{mm} / \mathrm{h})$ & $56 \pm 31.6$ & $50.2 \pm 29.4$ & ns \\
\hline CRP TO $(\mathrm{mg} / \mathrm{dL})$ & $3.3 \pm 3.3$ & $3.8 \pm 4.2$ & ns \\
\hline ESR T $6(\mathrm{~mm} / \mathrm{h})$ & $24.3 \pm 16.2$ & $29.9 \pm 20.4$ & ns \\
\hline CRP T 6 (mg/dL) & $0.6 \pm 0.7$ & $1.5 \pm 2.1$ & .01 \\
\hline ESR T $12(\mathrm{~mm} / \mathrm{h})$ & $22 \pm 15.4$ & $28.7 \pm 17.4$ & ns \\
\hline CRP T 12 (mg/du) & $0.2 \pm 0.2$ & $1 \pm 0.8$ & .000 \\
\hline Remission T6 & 27 & 7 & .000 \\
\hline $\begin{array}{l}\text { Prednisone dosage }(\mathrm{mg}) \\
\text { TO }\end{array}$ & $16.3 \pm 8.4$ & $15.5 \pm 6.6$ & ns \\
\hline $\begin{array}{l}\text { Prednisone dosage }(\mathrm{mg}) \\
\text { T6 }\end{array}$ & $5.9 \div 4.8$ & $7.5 \pm 5.1$ & ns \\
\hline $\begin{array}{l}\text { Prednisone dosage }(\mathrm{mg}) \\
\text { T12 }\end{array}$ & $2.3 \pm 2.5$ & $4.4 \pm 4.7$ & .04 \\
\hline Dyslipidemia & 9 & 12 & ns \\
\hline Hypertension & 21 & 21 & ns \\
\hline Obesity & 9 & 8 & ns \\
\hline Diabetes & 6 & 8 & ns \\
\hline Smokers & 3 & 3 & ns \\
\hline
\end{tabular}

T0: Bas eline; TG: Six months of follow up; T12: One year of follow up; ESR: erythrocyte sedimentation rate: CRP: C-Reactive Protein.

Conclusions: The sixth month of therapy is a crucial target for the management of PMR, because it can help to identify patients at greater risk of exacerbations, which may benefit from a tighter follow-up and a more aggressive therapeutic strategy. Among prognostic factors female sex and high CRP values at sixth months appear to be associated with higher relapse risk and a longer duration of treatment.

References:

[1] Dejaco C, Singh YP, European League Against Rheumatism; American College of Rheumatology, 2015 Recommendations for the management of polymyalgia rheumatica: a European League Against Rheumatism/American College of Rheumatology collaborative initiative. Ann Rheum Dis. 2015 Oct;74(10):1799-807. doi: 10.1136/annrheumdis-2015-207492.
[2] Dasgupta B, Cimmino MA, Matteson EL. 2012 provisional classification criteria for polymyalgia rheumatica: a European League Against Rheumatism/American College of Rheumatology collaborative initiative, Ann Rheum Dis. 2012 Apr;71(4):484-92. doi: 10.1136/annrheumdis-2011-200329.

Disclosure of Interest: None declared

DOI: 10.1136/annrheumdis-2017-eular.6262

\section{FRI0320 PREDICTIVE VALUE OF PLATELET TO LYMPHOCYTE RATIO IN RENAL INVOLVEMENT IN PATIENTS WITH GRANULOMATOSIS WITH POLYANGIITIS}

H. Kucuk ${ }^{1}$, D. Tecer ${ }^{2}$, O. Varan ${ }^{1}$, H. Babaoglu ${ }^{1}$, S.C. Guven ${ }^{2}$, A. Tufan ${ }^{1}$,

S. Haznedaroglu ${ }^{1}$, M.A. Özturk ${ }^{1}$, B. Goker ${ }^{1}$. ${ }^{1}$ Department of Internal Medicine, Division of Rheumatology; ${ }^{2}$ Department of Physical and Rehabilitation Medicine, Division of Rheumatology, Gazi University Faculty of Medicine, Ankara, Turkey

Background: Granulomatosis with polyangiitis (GPA) is a granulomatous necrotizing vasculitis with high morbidity and mortality. Anti-neutrophil cytoplasmic antibody (ANCA) is a rvaluable diagnostic marker, however its titer lacks predictive value for the severity of organ involvement. Platelet to lymphocyte ratio (PLR) and mean platelet volume has been regarded as a potential marker in assessing systemic inflammation.

Objectives: We aimed to investigate PLR and MPV as inflammatory marker in patients with GPA.

Methods: GPA patients and age-sex matched healthy controls were included. Demographic, clinical and laboratory information were extracted from medical records. Erythrocyte sedimentation rate (ESR), C-reactive protein (CRP), white blood cell (WBC), platelets (PLT), lymphocyte and neutrophils counts and glomerular filtration rate (GFR) were recorded. PLR was calculated. Disease activity was assessed with Birmingham Vasculitis Activity Score for WG vasculitis (BVAS/WG).

Results: 56 patients with GPA and 53 healty controls were included. Clinical characteristics and laboratory findings of the study population are shown in Table 1. ESR, CRP, MPV and PLR were significantly higher in patients with GPA than controls. PLR positively correlated with ESR and CRP ( $r: 0.389, p: 0.005$ and $r: 0.512 p<0.001$, respectively). In contrast, MPV negatively correlated with ESR and CRP ( $r:-0.308, p: 0.028$ and r:-0.337 p:0.014, respectively). There were no significant correlation between PLR, MPV and BVAS/WG. Patients with renal involvement had statistically significantly higher PLR than patients without renal involvement $(303.01 \pm 287.33$ vs $177.98+75.43$, p: 0.020 respectively). Moreover PLR negatively correlated with glomerlar filtration rate ( $r:-0.266$ and $p: 0.009)$. Receiver operating characteristic curve of PLR, ESR and CRP for differentiating renal involvement is presented in Figure 1. Area Under Curves (AUCs) for PLR, CRP and ESR were 0.703 (95\% confidence interval [Cl], 0.558-0.849, $\mathrm{p}=0.016$ ), 0.577 (95\% Cl: $0.416-0.738, p=0.362$ ), 0.508 (95\% Cl: $0.337-0.678, p=0.929$ ), respectively. The cutoff level of PLR was 204 (sensitive $65.6 \%$, specifity $62.5 \%$, positive predictive value $70 \%$, negative predictive value $57.7 \%$ ). Patients with alveolar hemorrhage tended to have higher PLR but this difference did not reach statistically significance $(266.60+182.90$ vs $240.61+252.43 p=0.382$, respectively).

Conclusions: Results suggest that PLR exhibit favorable diagnostic performance in predicting renal involvement in patients with GPA

Table 1. Clinical characteristics and laboratory findings of the patients and healthy controls

\begin{tabular}{l|l|l|l}
\hline & GPA patients & Controls & p value \\
\hline Age (years) & $48.14 \pm 14.09$ & $46.77 \pm 14.14$ & 0.614 \\
\hline Males (n) & $33(58.9 \%)$ & $26(49.1 \%)$ & 0.034 \\
\hline WBC $\left(\times 10^{3} /\right.$ uL) & $12359.96 \pm 6604.92$ & $7230.80 \pm 1630.33$ & $<0.001$ \\
\hline Neutrophils & $9267.74 \pm 5701.73$ & $4285.73 \pm 1597.18$ & $<0.001$ \\
\hline Lymphocytes & $1805.64 \pm 986.24$ & $2311.22 \pm 581.93$ & $<0.001$ \\
\hline Platelets & $343640 \pm 174905.10$ & $234939.02 \pm 57204.24$ & $<0.001$ \\
\hline ESR & $54.19 \pm 35.42$ & $10.12 \pm 7.66$ & $<0.001$ \\
\hline CRP & $64.18 \pm 72.11$ & $3.42 \pm 1.59$ & $<0.001$ \\
\hline MPV & $7.73 \pm 0.96$ & $8.76 \pm 1.10$ & \\
\hline PLR (mean +SD) & $253.99 \pm$ & $104.79 \pm 25.23$ & $<0.001$ \\
\hline
\end{tabular}

Figure. ROC curve of PLR, ESR and CRP for differentiating renal involvement

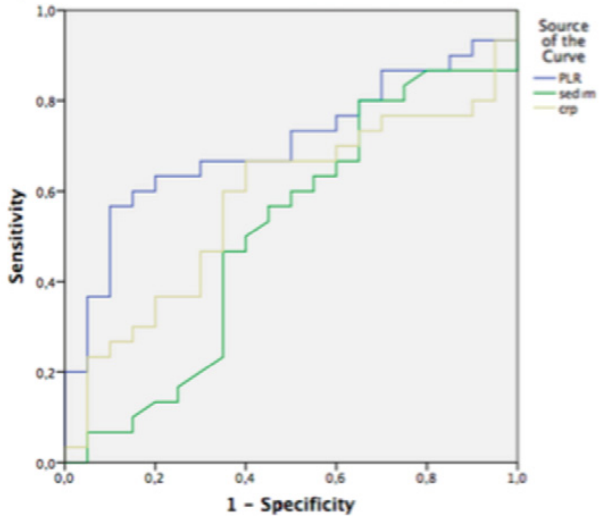


Disclosure of Interest: None declared

DOI: 10.1136/annrheumdis-2017-eular.6473

\section{FRI0321 CIRCULATING IL-6 AND OTHER METABOLIC BIOMARKERS COMPARING EFFECTS OF MODIFIED-RELEASE PREDNISONE (MR) AND IMMEDIATE-RELEASE PREDNISOLONE (IR) IN NEW GCA}

E. Miler ${ }^{1}$, S. Mapplebeck ${ }^{1}$, C. Mackerness ${ }^{1}$, L. Wilson ${ }^{1}$, T. Aung ${ }^{1}$, D. Gayford ${ }^{1}$, J.P. Schofield ${ }^{2}$, B. Dasgupta ${ }^{1} .{ }^{1}$ Southend University Hospital NHS Foundation Trust, Westcliff-on-Sea; ${ }^{2}$ Napp Pharmaceuticals Limited, Cambridge Science Park, Milton Road, United Kingdom

Background: GCA may be an interleukin-6 (IL-6) driven disease and IL-6 blockade is emerging as an exciting therapy of IL-6. ${ }^{1}$ We measured serial IL-6 levels in new patients with GCA treated in an RCT of modified-release prednisone (MR) versus immediate-release prednisolone (IR) used in a tapering regimen conforming to BSR quidelines. , $^{2,3}$

Methods: Patients $(n=12)$ were randomised into two treatment arms (7 MR, 5 IR) and followed up over 26 weeks. IL- 6 samples were collected at 9am at weeks 4 , 10, 18 and 26 and were measured using Beckman Coulter IL-6 immunoassay, validated in a controlled study according to ACB criteria. We also measured bone markers (CTX, P1NP, vitamin D), HbA1c, cortisol, ACTH and PTH.

Results: Significantly higher overall mean IL-6 levels were seen in the IR arm $(n=5)$ compared to MR $(n=7)$ [unpaired two-tailed Student's $t$ test]. IL-6 levels in both arms were lowest between weeks $4-10$ and continued to decrease in the IR arm to week 26, whereas lower but constant levels were seen in the MR arm (Figure)

Mean CTX concentration was significantly higher at week $4(\mathrm{M}=0.29, \mathrm{SE}=0.04)$ compared to Week 26 ( $M=0.13, S E=0.02) p=0.002$. No significant difference was seen between treatment arms.

Patients on MR had complete suppression of ACTH compared to IR $(p<0.05)$ without a significant difference between groups in 9 am cortisol levels $(p=0.3412)$. No significant differences were seen in levels of vitamin D, calcium, PTH, ESR, CRP, or HbA1c.

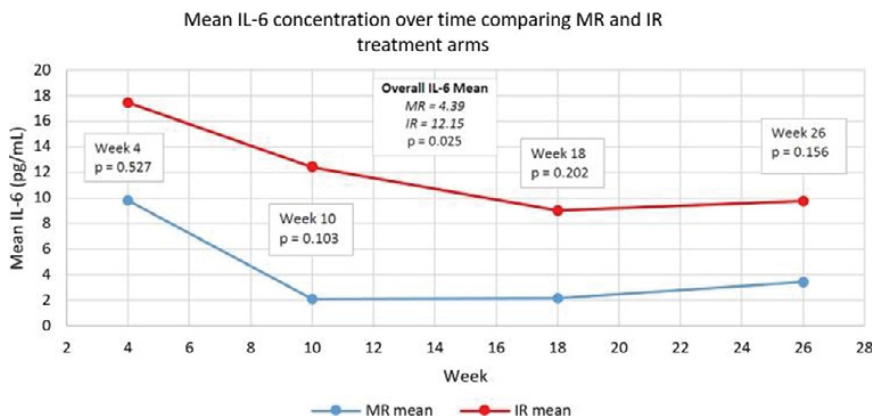

Conclusions: Our study suggests that elevated levels of II-6 are better suppressed by MR prednisone therapy compared to IR prednisolone in new GCA. Bone resorption marker CTX was significantly reduced in both treatment arms. ACTH suppression with MR prednisone may reflect a greater impact on the HPA axis although cortisol levels were not affected.

Our findings suggest that MR prednisone may warrant further clinical trial investigation in GCA.

\section{References:}

[1] Dasgupta, B. and Panayi, G.S., 1990. Interleukin-6 in serum of patients with polymyalgia rheumatica and giant cell arteritis. British journal of rheumatology, 29(6), pp. 456-458.

[2] Spies, C.M., Straub, R.H., Cutolo, M. and Buttgereit, F., 2014. Circadian rhythms in rheumatology-a glucocorticoid perspective. Arthritis research \& therapy, 16 Suppl 2, pp. S3.

[3] Dasgupta, B., Borg, F.A., Hassan, N., Alexander, L., Barraclough, K., Bourke, B., Fulcher, J., Hollywood, J., Hutchings, A., James, P., Kyle, V., Nott, J., Power, M., Samanta, A. and BSR and BHPR Standards, Guidelines and Audit Working Group, 2010. BSR and BHPR guidelines for the management of giant cell arteritis. Rheumatology (Oxford, England), 49(8), pp. 1594-1597.

Acknowledgements: Napp Pharmaceuticals Limited, Beckman Coulter, Gabriel Labinjo for technical support.

Disclosure of Interest: E. Miler: None declared, S. Mapplebeck: None declared, C. Mackerness: None declared, L. Wilson: None declared, T. Aung: None declared, D. Gayford: None declared, J. P. Schofield Grant/research support from: Napp Pharmaceuticals Limited and Napp distributes prednisone MR in U.K.

(Lodotra), B. Dasgupta: None declared

DOI: 10.1136/annrheumdis-2017-eular.3550

\section{FRI0322 ASSESSMENT OF DAMAGE AND PROGNOSIS IN PATIENTS WITH ADULT IGA VASCULITIS: RETROSPECTIVE MULTICENTERED COHORT STUDY}

F. Alibaz-Oner ${ }^{1}$, A. Omma ${ }^{2}$, A. Sarı ${ }^{3}$, O. Karadag ${ }^{3}$, D. Uskudar Cansu ${ }^{4}$, C. Bes ${ }^{5}$, F. Yildiz ${ }^{6}$, M.F. Oksuz ${ }^{7}$, S. Yilmaz ${ }^{8}$, A. Balkarli ${ }^{9}$, S. Ureyen ${ }^{10}$, H. Direskeneli ${ }^{1}{ }^{1}$ Rheumatology, Marmara University, School of Medicine, Istanbul; ${ }^{2}$ Rheumatology, Ankara Numune Education and Research Hospital;

${ }^{3}$ Rheumatology, Hacettepe University, School of Medicine, Ankara;

${ }^{4}$ Rheumatology, Osmangazi University, School of Medicine, Eskisehir;

${ }^{5}$ Rheumatology, Bakırkoy Sadi Konuk Education and Research Hospital, Istanbul; ${ }^{6}$ Rheumatology, Van Education and Research Hospital, Van;

${ }^{7}$ Rheumatology, Uludag University, School of Medicine, Bursa; ${ }^{8}$ Rheumatology, Selcuk University, School of Medicine, Konya; ${ }^{9}$ Rheumatology, Antalya Education and Research Hospital, Antalya; ${ }^{10}$ Rheumatology, Sakarya Education and Research Hospital, Sakarya, Turkey

Background: IgA Vasculitis is a leukocytoclastic vasculitis involving small vessels with depositions of immune complexes containing IgA. There is limited data for the prognosis of adult IgA Vasculitis, with also no damage assessment.

Objectives: We aimed to evaluate the clinical characteristics, treatment, outcome and damage of patients with adult IgA Vasculitis.

Methods: We assembled a retrospective cohort of patients with adult IgA Vasculitis, from tertiary Rheumatology Centers in Turkey. All data were abstracted from medical records. Birmingham Vasculitis Activity Score (BVAS),prognostic Five Factor Score (FFS) and vasculitis damage index (VDI) were calculated.

Results: The study included 52 (male/female:40/12) patients with adult IgA Vasculitis. The mean age was $42.2 \pm 17$ years. Infection history within 6 weeks before presentation was present in $22(42.3 \%)$ patients (18 upper respiratory tract, 3 gastrointestinal and 1 urinary tract). Cutaneous manifestations were the most common clinical manifestations (Table 1). All patients were treated with oral glucocorticoids (GC).As additional immunosuppressive agents, azathiopirine was given to $21(40.4 \%)$ and pulse cyclophosphamide to $11(21.2 \%)$ patients. Twenty-eight patients (53.9\%) had follow-up of 28.6 months. Five (17.8\%) patients relapsed during follow-up. While 3 relapses were major, 2 of them were minor relapses. At the last visit, disease status was evaluated as active or treatment failure by the treating physician in $6(21.4 \%)$ patients. Mortality was $3.6 \%(n=1)$ during follow-up, due to pneumonia. The mean VDI score was 0.6 in the last visit. Nine (32.1\%) patients had at least one damage item at the end of follow-up period.

Table 1. Clinical characteristics of patients with adult IgA Vasculitis

\begin{tabular}{lc}
\hline & Adult IgA Vasculitis $(\mathrm{n}=52)$ \\
\hline Laboratory parameters & \\
Erythrocyte Sedimentation Rate $\left(\mathrm{mm} / \mathrm{hour}^{*}\right.$ & $32.7 \pm 22$ \\
C-reactive protein $\left(\mathrm{mg} / \mathrm{l}^{\dagger}\right.$ & $25.2(1-94.9)$ \\
Proteinuria $(>300 \mathrm{mg} / 24$ hours) & $28(53.9 \%)$ \\
Creatinine $(\mathrm{mg} / \mathrm{dl})^{\star}$ & $0.9 \pm 0.4$ \\
Clinical Manifestations, $\mathrm{n} / 52(\%)$ & \\
Fever & $7(13.5 \%)$ \\
Weight loss & $14(26.9 \%)$ \\
Myalgia/Weakness/Leg tenderness & $24(46.2 \%)$ \\
Arthritis and/or arthralgia & $46(88.5 \%)$ \\
Neurologic manifestations & $1(1.9 \%)$ \\
Testicular pain or tenderness & $3(5.8 \%)$ \\
Recent onset or severe hypertension & $2(3.8 \%)$ \\
Cutaneous Manifestations & $48(92.3 \%)$ \\
Gastrointestinal manifestations & $39(75 \%)$ \\
FFS $=0$ & $29(55.8 \%)$ \\
FFS $=1$ & $15(28.8 \%)$ \\
FFS $\geq 2$ & $8(15.4 \%)$ \\
BVAS score at diagnosis ${ }^{*}$ & $4.1 \pm 1.7$ \\
\hline
\end{tabular}

FFS: Five Factor Score, BVAS: Birmingham Vasculitis Activity score. ${ }^{*}$ Mean $\pm \mathrm{SD}$; ${ }^{\dagger}$ Median (Minimum-maximum.)

Conclusions: Our results showed that approximately one fifth of patients with adult IgA Vasculitis had relapses during follow-up. At the end of follow-up, one third of patients had at least one damage item. Although, $45 \%$ of patients had $F F S \geq 1$, the mortality rate was observed to be low in the present study.

Disclosure of Interest: None declared

DOI: 10.1136/annrheumdis-2017-eular.3865

\section{FRI0323 COMPARISON OF BIOPSY PROVEN GIANT CELL ARTERITIS IN NORTH AMERICA AND SOUTHERN EUROPE: A POPULATION-BASED STUDY}

F. Muratore $^{1}$, C.S. Crowson ${ }^{2}$, L. Boiardi ${ }^{1}$, M.J. Koster ${ }^{2}$, G. Restuccia ${ }^{1}$, T.A. Kermani ${ }^{3}$, E.L. Matteson ${ }^{2}$, C. Salvarani ${ }^{1}$, K.J. Warrington ${ }^{2} .{ }^{1}$ Rheumatology Unit, Arcispedale Santa Maria Nuova IRCCS, Reggio Emilia, Italy; ${ }^{2}$ Division of Rheumatology, Mayo Clinic, Rochester, MN; ${ }^{3}$ Department of Medicine, David Geffen School of Medicine, University of California, Los Angeles, United States

Objectives: To compare clinical characteristics, treatment, long-term follow-up and prognosis of two population-based cohorts of patients with biopsy-proven giant cell arteritis (GCA) from Olmsted County, Minnesota, USA (Olmsted cohort) and the Reggio Emilia area, Northern Italy (Reggio cohort).

Methods: All patients residing in Olmsted County and the Reggio Emilia area 